\title{
In Vitro Regeneration of Oat (Avena sativa L.) Using Different Explants
}

\author{
M.D. Salunke ${ }^{1}$, B.U. Rathod $^{2 *}$ and N.R. Dattagonde ${ }^{1}$ \\ ${ }^{1}$ Department of Crop Science, Mahatma Gandhi College of Agricultural Biotechnology, \\ Nanded, Maharashtra, India \\ ${ }^{2}$ Department of Biotechnology, University of Agricultural Sciences, Dharwad, Karnataka, India \\ *Corresponding author
}

\begin{tabular}{|c|c|}
\hline & A B S T R A C T \\
\hline & In present study efforts were made to improve the regeneration protocol in the oat cultivars \\
\hline Keywords & $\begin{array}{l}\text { JO- } 1 \text { and OS- } 6 \text {. In mature embryo and immature embryo, callus induction was observed } \\
\text { maximum on MS medium supplemented with } 2,4-\mathrm{D}(4.0 \mathrm{mg} / \mathrm{L} \text { and } 6 \mathrm{mg} / \mathrm{L}) \text { respectively }\end{array}$ \\
\hline $\begin{array}{l}\text { Oat, Regeneration, } \\
\text { 2,4-D, BAP, IBA. } \\
\text { NAA. }\end{array}$ & $\begin{array}{l}\text { whereas, in case of embryogenic calli MS medium supplemented with } 2,4-\mathrm{D}(6.0 \mathrm{mg} / \mathrm{L}) \\
\text { was found to be best and in organogenesis MS medium supplemented with BAP (2- } \\
4 \mathrm{mg} / \mathrm{L}) \text { and }\end{array}$ \\
\hline Article Info & was observed maximum on MS medium supplemented with 2,4-D $(2.0 \mathrm{mg} / \mathrm{L})$ whereas, in \\
\hline $\begin{array}{l}\text { Accepted: } \\
07 \text { October } 2017 \\
\text { Available Online: } \\
10 \text { December } 2017\end{array}$ & $\begin{array}{l}\text { be better and in organogenesis MS medium supplemented with BAP }(2-4 \mathrm{mg} / \mathrm{L}) \text { and NAA } \\
(0.1 \mathrm{mg} / \mathrm{L}) \text { was found to be better. Among different genotypes JO-1 produced maximum } \\
\text { number of induced calli, embryogenic calli as well as organogenic calli. While, genotype } \\
\text { OS-6 performed moderately for initiation of calli. }\end{array}$ \\
\hline
\end{tabular}

\section{Introduction}

Cultivated oat (Avena sativa L.) is an important agronomic cereal crop. The oat crop is primarily produced for animal feed and human food, but recent research has elevated its potential dietary value for human consumption. Oat ranks sixth in world cereal production following wheat, maize, rice, barley and sorghum (Choubey et al., 1996). It is important winter forage in many parts of the world and is grown as a multipurpose crop for grain, forage or as a rotation crop. It has excellent growth habit, quick recovery after cutting and good quality herbage. It is a palatable, succulent and nutritious fodder crop with excellent protein quality. Oat requires a long and cool season for its growth; therefore, it is successfully grown in the plains and hilly areas of the country. The crop occupies maximum area in Uttar Pradesh (34\%) followed by Punjab (20\%), Bihar (16\%), Haryana (9\%) and Madhya Pradesh (6\%) (Choubey et al., 1996). Currently, oat remains an important grain and forage crop in many parts of the world and grown on 13.2 million hectares with a grain production of 26.2 million metric tons in 2003 (USDA, http://fas.usda.gov/psd). The Russian federation is the largest producer followed by Canada and the USA. Land area devoted to oat has fallen substantially in the past several decades with oat being displaced by higher value crops, such as soybean in the USA. 
Also, the role of oat as a major protein source in animal feed rations has been displaced by higher protein meals of soybean and other oilseed crops.

Crop and plant improvement is a major area of commercial interest. A great deal of efforts has been made towards the development of new cultivars of oat with improved disease, pest and herbicide resistance. Genetic improvement of commercially important oat cultivars through classical breeding is laborious and time-consuming, expensive and sometimes even unsuccessful.

The new gears of biotechnology such as genetic transformation has enabled us to insert any gene for any quality character such as delayed flowering, early maturity and increment in girth etc. as well as against biotic and abiotic stresses. A remarkable progress has been made in the development of gene transfer technology (Somers et al., 1992), which ultimately has resulted in the production of large number of transgenic plants both in dicots and monocots.

Potential benefits from these transgenic plants include higher yield, enhanced nutritional value reduction in pesticide and fertilizer use. Transgenic oat plants have been obtained using particle bombardment methods of gene transfer (Pawlowski and Somers, 1998). DNA integration patterns in transformed plant tissue obtained via particle bombardment tend to be highly variable and multiple or fragment copies of introduced DNAs are common, especially when older cultures are targeted. Since, the pre-requisite for any genetic engineering process is the availability of an efficient in vitro regeneration system from cell and callus cultures especially the somatic embryogenesis. Apart from genetic transformation, somatic embryos may be used for the production of artificial seeds facilitating large-scale multiplication of elite oat cultivars. Whatever the transformation system is employed, efficient system for embryogenic callus induction and shoot regeneration have been considered basic step in production of stable transgenic plants (Gless et al., 1998). Various tissue culture techniques are being applied for varietal development of cereal crops including oat in different countries (Kim et al., 2004). Among these techniques, anther culture, protoplast fusion, leaf culture, root culture and dehusked seed culture are important in oat an ancillary techniques for the creation of novel oat varieties.

There are several coordinated public breeding programs focusing on the genetic enhancement of oat. Despite these efforts, yield and quality losses due to stress, pathogens and insects continue to occur. The continued development of biotechnological approaches to genetic study and manipulation of oat would aid in oat crop improvement efforts

In present investigation we standardized the regeneration protocol for the cultivars JO-1 and OS-6 which are considered to be good cultivars in the India. However, no previous studies have been performed to standardize regeneration protocols using these two cultivars.

\section{Materials and Methods}

Seeds of two oat varieties were obtained from the All India Coordinated Forage Research Project (ICAR), Department of Agronomy, JNKVV, Jabalpur. Plant material consisting of mature embryo and leaf base were obtained from in vitro germinated seeds. Initially oat seeds were washed thoroughly with tap water in order to remove dust and other particles followed by washing in distilled water added 
with 2-3 drops of Tween-20 for $20 \mathrm{~min}$. The seeds were rinsed with distilled water 8-9 times. Further sterilization was carried out inside the laminar air flow chamber. Seeds were treated with $70 \%$ ethyl alcohol for 2 min followed by $0.5 \% \mathrm{HgCl}_{2}$ solution for 5 min. Sterilized seeds were washed thoroughly with autoclaved distilled water for 4-5 times to overcome the poisonous effect of $\mathrm{HgCl}_{2}$. Finally, seeds were soaked in sterile water for 1-2 min prior to inoculation in to MS medium without any growth regulator.

\section{Mature embryo as explants}

The mature embryos were removed from the imbibed seeds and placed, scutellum-up, on MS medium with different combinations of growth regulators as mentioned in Table 1 (Fig. 1). Plates were incubated at $25^{\circ} \mathrm{C}$ for 15 days in darkness. For the regeneration, embryogenic part of the callus was cut into small pieces approximately $2-3 \mathrm{~mm}$ in size and inoculated on MS regeneration media (MS2B.1N) and incubated for 5 weeks at $25^{\circ} \mathrm{C}$ in a $16 \mathrm{~h}$ light and $8 \mathrm{~h}$ dark photoperiod. Small shoots $(2-3 \mathrm{~cm})$ were subcultured on growth regulator-free root regeneration medium

\section{Leaf base as explants}

Leaf-base segments were taken from 3-4 dayold seedlings. The leaves were separated from coleoptiles and sequentially cut into $1 \mathrm{~mm}$ transverse sections, starting from the original leaf base with a scalpel in a sterile Petri dish, a sheet of millimetre paper was placed underneath to allow accurate sizing during dissection. Segments 1-6 starting from base (1 $\mathrm{mm}$ each) were compared for their embryogenic callus induction efficiency. Only those calli containing distinct embryogenic structures under the stereomicroscope were considered to be embryogenic. Other types of calli (e.g. watery, translucent callus) were discarded. On the basis of this comparison, only segments 1-3 were used in the medium optimization experiment. After about 6 weeks, calli were transferred to shoot induction medium (for regeneration) with different combinations of growth regulators (Table 1) and cultured in the light at $25^{\circ} \mathrm{C}$. Shoots were subcultured on growth regulatorfree root regeneration medium. Plants were kept under laboratory conditions for 10-15 days before they were transferred to the greenhouse for hardening

\section{Results and Discussion}

Two separate experiments were conducted with two different explants of oat viz. mature embryo and leaf base. Explants of two genotypes viz. JO-1 and OS-6 were cultured on different combinations of MS media. The media were selected on the basis of preliminary experiments conducted to screen suitable plant growth regulators and their combinations for in vitro response. The basal MS medium was fortified with different combinations of BAP, NAA, IBA and 2,4-D in varying concentrations. Ten different combinations of culture media were used for each explant isolated from two accessions. During present investigation, observations were recorded for callus induction, embryogenic calli and organogenic calli formation and plant regeneration abilities.

\section{Mature embryo culture}

Mature embryos were cultured on ten different combinations of MS medium. Callus induction, embryogenic calli and organogenic calli formation were observed from all the accessions and on all combinations of MS medium, their frequency varied among the different media combinations and accessions. The effects of culture media and accessions on mature embryo cultures are presented in Table 1. 
The callus induction from mature embryo cultures varied from $95 \%$ to $10 \%$ (Table 1). Maximum callus induction was evident from JO-1 (95.0\%) followed by and minimum from OS-6 (10\%). In terms of the culture media response to in vitro culture, the performance of culture media MS6D (95.0\%) followed by MS4D $(85.0 \%)$ was found the best in terms of callus initiation.

The minimum response was observed in inoculation media MS0 and (10\%). However, rest of culture media performed moderately.

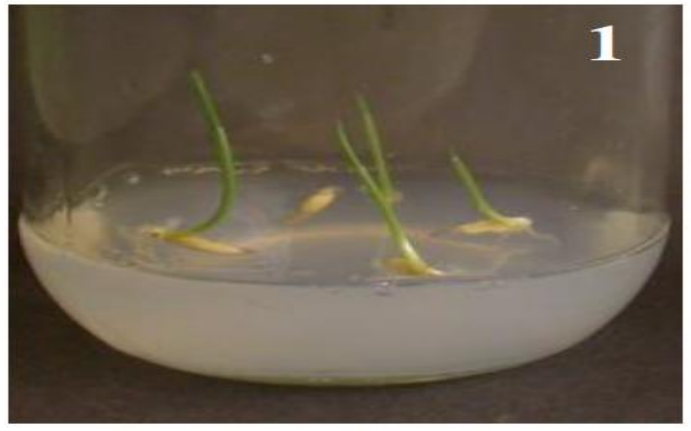

Fig. 1 Oat seed germination

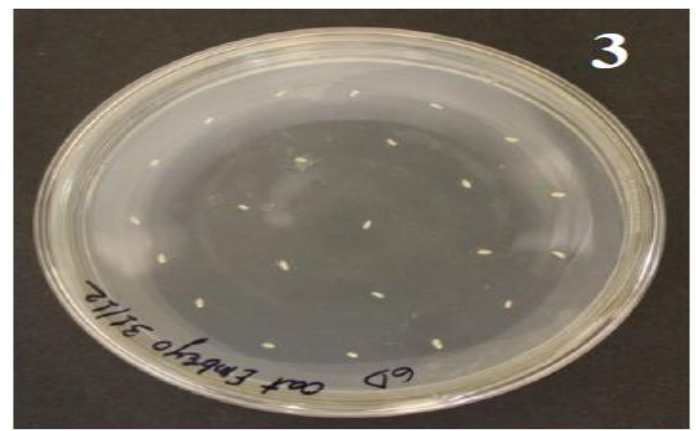

Fig. 3 Excised Oat Embryos

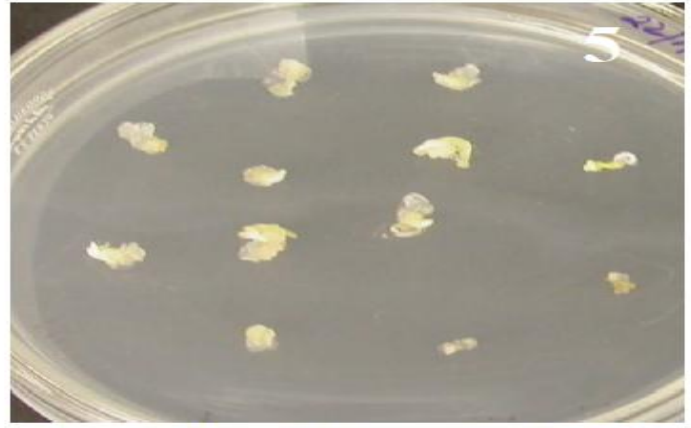

Fig. 5 Callus initiation in excised Oat embryos
The embryogenic calli formation from mature embryo cultures varied from $95 \%$ to $0 \%$ (Table 1). Among Two accessions, maximum embryogenic calli formation was observed from JO-1 (95.0\%) and minimum from OS-6 $(0 \%)$. In terms of the culture media response to in vitro culture, the performance of culture media MS2D (95.0\%) followed by MS4D $(80 \%)$ was found to be most responding for embryogenic callus initiation. Embryogenic callus was not observed from the explants of JO-1 cultured on MSO.

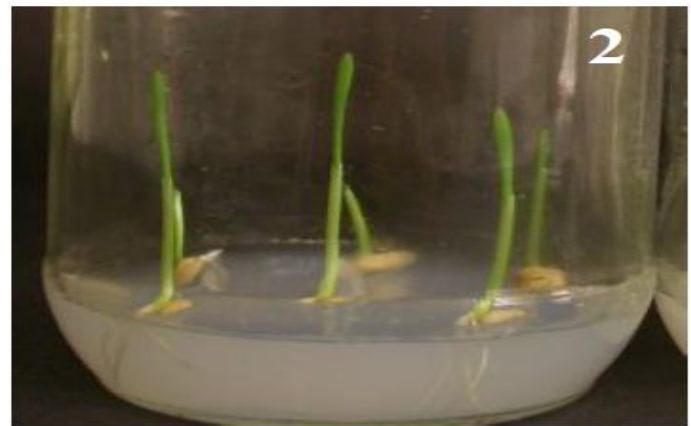

Fig. 2 In vitro germinated 6 Day old Oat seedlings

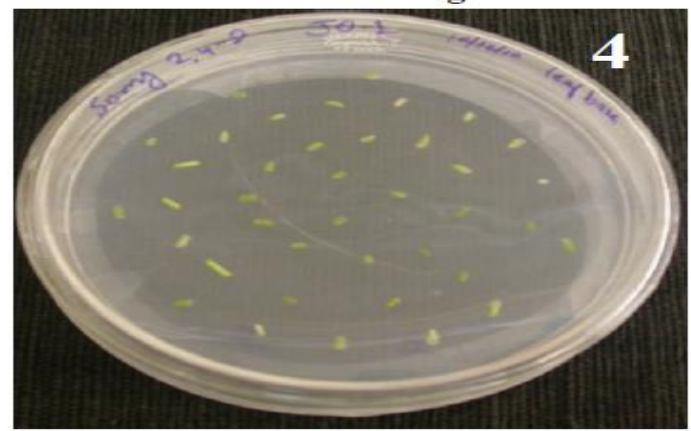

Fig. 4 Excised Oat Leaf Bases

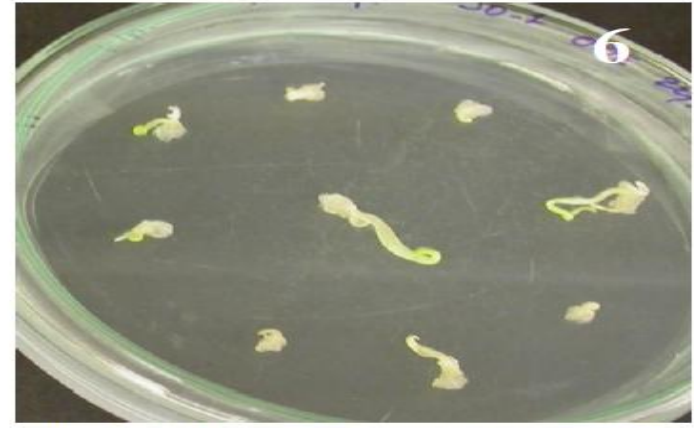

Fig. 6 Callus Initiation in Excised Oat Leaf Bases

PLATE-I 


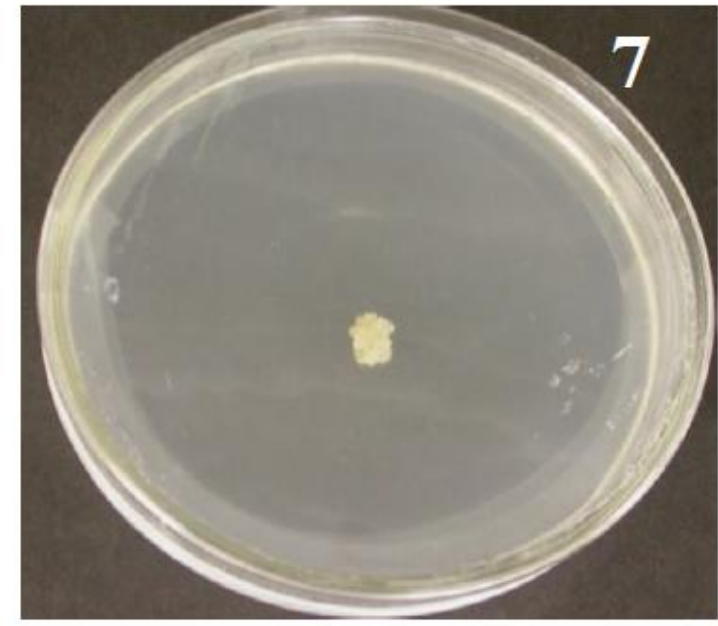

Fig. 7 Embyogenic calli formation

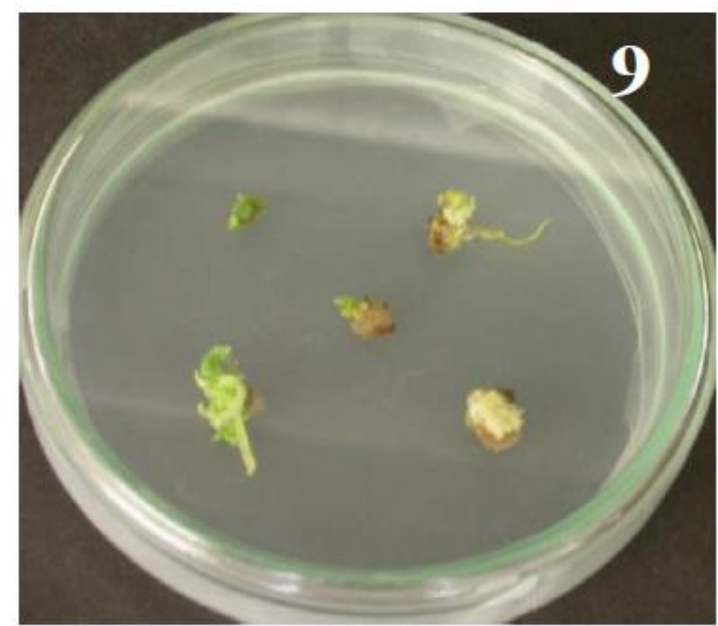

Fig. 9 Organogenic Calli formation

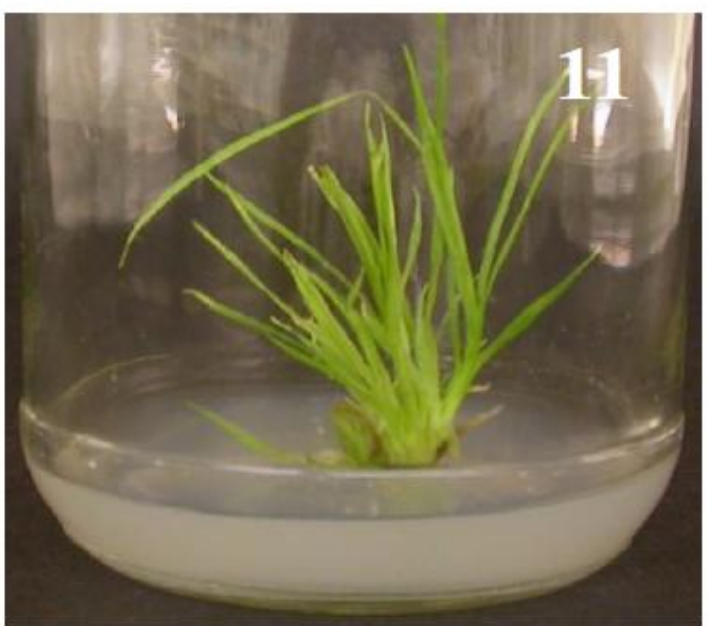

Fig. 11 Multiple shoot formation

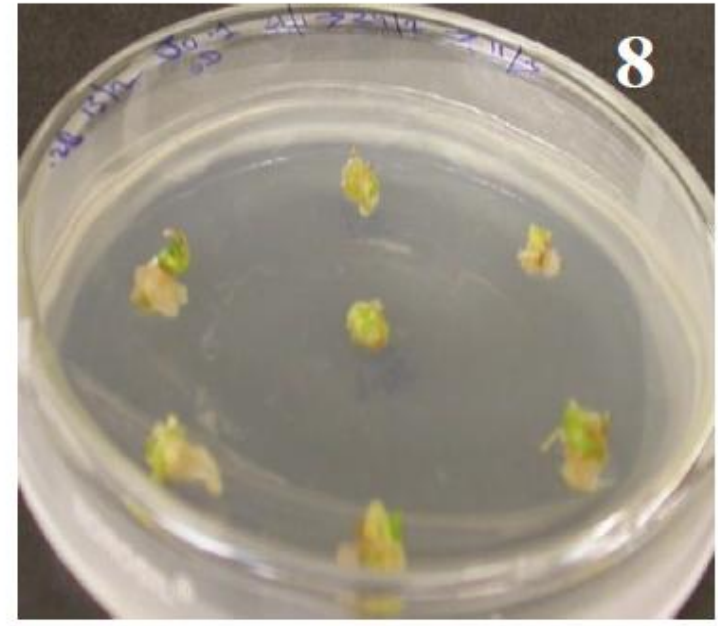

Fig. 8 Organogenic Calli formation

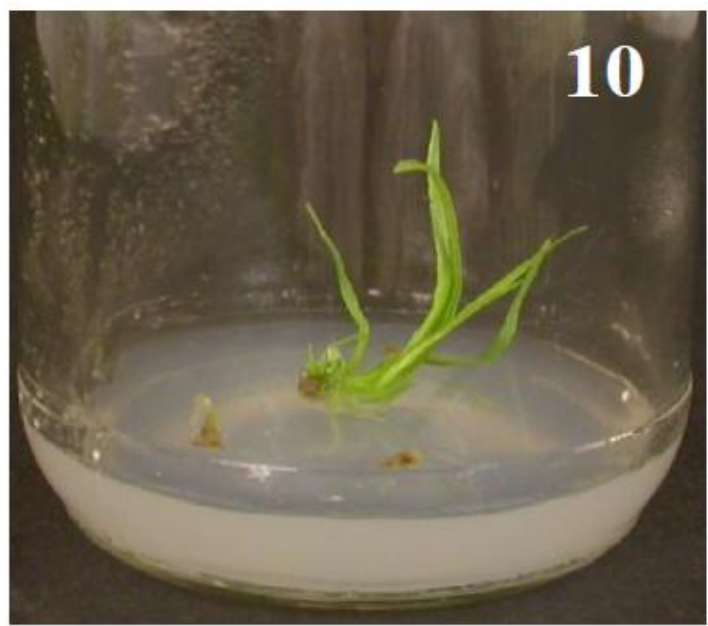

Fig. 10 Shoot initiation

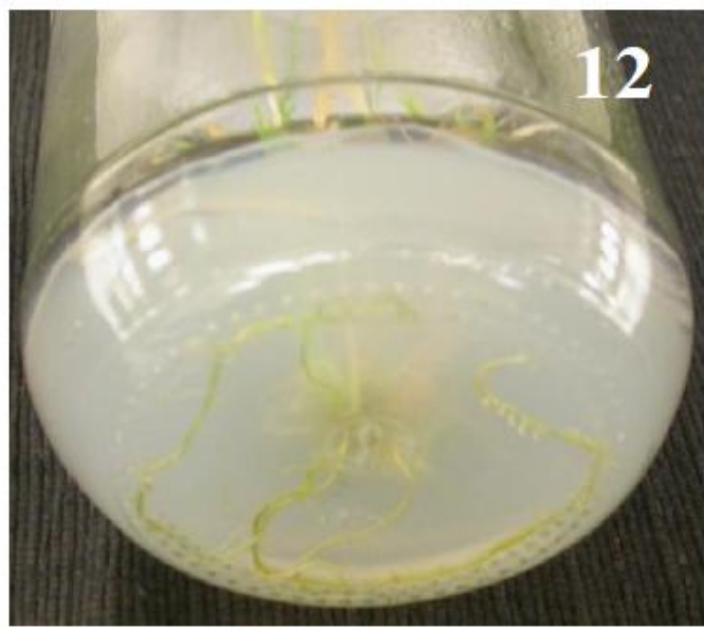

Fig. 12 Root formation

PLATE-II 
Table.1 Concentrations of plant growth regulators fortified with MS culture media for preliminary experiments

\begin{tabular}{|c|c|c|c|c|c|}
\hline \multirow{2}{*}{ Sr. No. } & \multirow{2}{*}{ Media } & \multicolumn{4}{|c|}{ Growth regulators (mg/L) } \\
\cline { 3 - 6 } & & 2,4-D & NAA & BAP & IBA \\
\hline 1 & MS0 (Control) & - & - & - & - \\
\hline 2 & MS2D & 2.0 & - & - & - \\
\hline 3 & MS4D & 4.0 & - & - & - \\
\hline 4 & MS6D & 6.0 & - & - & - \\
\hline 5 & MS2B.1N & - & 0.1 & 2.0 & - \\
\hline 6 & MS3B.1N & - & 0.1 & 3.0 & - \\
\hline 7 & MS4B1N & - & 0.1 & 4.0 & - \\
\hline 8 & MS1IBA & - & - & - & 1.0 \\
\hline 9 & MS2IBA & - & - & - & 2.0 \\
\hline 10 & MS3IBA & - & - & - & 3.0 \\
\hline
\end{tabular}

Table. 2 Observation on in vitro regeneration of oat cultivars

\begin{tabular}{|c|c|c|c|c|c|c|c|c|c|c|c|c|c|c|}
\hline \multirow{4}{*}{$\begin{array}{l}\text { Sr. } \\
\text { No. }\end{array}$} & \multirow{4}{*}{ Media } & \multirow{4}{*}{ 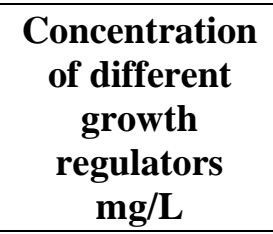 } & \multicolumn{12}{|c|}{ No. of explants showing different growth response per 20 explants } \\
\hline & & & \multicolumn{4}{|c|}{ Callus Induction } & \multicolumn{4}{|c|}{$\begin{array}{c}\text { Embryogenic Callus } \\
\text { Formation }\end{array}$} & \multicolumn{4}{|c|}{ Organogenesis } \\
\hline & & & \multicolumn{2}{|c|}{ JO-1 } & \multicolumn{2}{|c|}{ OS-6 } & \multicolumn{2}{|c|}{ JO-1 } & \multicolumn{2}{|c|}{ OS-6 } & \multicolumn{2}{|c|}{ JO-1 } & \multicolumn{2}{|c|}{ OS-6 } \\
\hline & & & ME & LB & ME & $\mathbf{L B}$ & ME & $\mathbf{L B}$ & ME & $\mathbf{L B}$ & ME & LB & ME & LB \\
\hline 1 & $\begin{array}{c}\text { MS0 } \\
\text { (Control) }\end{array}$ & $\begin{array}{l}\text { Without GR } \\
\text { (Control) }\end{array}$ & 2 & 1 & 2 & 1 & 0 & 1 & 0 & 1 & 3 & 3 & 2 & 2 \\
\hline 2 & MS2D & 2,4-D $2 \mathrm{mg} / \mathrm{L}$ & 10 & 9 & 8 & 8 & 19 & 18 & 16 & 15 & 3 & 2 & 2 & 1 \\
\hline 3 & MS4D & $\mathrm{g} / \mathrm{L}$ & 17 & 14 & 15 & 12 & 16 & 14 & 13 & 11 & 3 & 3 & 2 & 2 \\
\hline 4 & MS6D & $2,4-\mathrm{D} 6 \mathrm{mg} / \mathrm{L}$ & 19 & 17 & 17 & 16 & 11 & 9 & 7 & 6 & 3 & 2 & 2 & 1 \\
\hline 5 & MS2B.1N & $\begin{array}{l}\text { BAP } 2+\mathrm{NAA} \\
0.1 \mathrm{mg} / \mathrm{L}\end{array}$ & 5 & 3 & 3 & 2 & 6 & 4 & 4 & 3 & 3 & 4 & 3 & 4 \\
\hline 6 & MS3B.1N & $\begin{array}{c}\text { BAP } 3+\text { NAA } \\
0.1 \mathrm{mg} / \mathrm{L}\end{array}$ & 6 & 4 & 4 & 3 & 8 & 5 & 6 & 4 & 4 & 3 & 3 & 3 \\
\hline 7 & MS4B.1N & $\begin{array}{c}\text { BAP } 4+\text { NAA } \\
0.1 \mathrm{mg} / \mathrm{L}\end{array}$ & 8 & 4 & 6 & 5 & 10 & 6 & 8 & 7 & 4 & 3 & 3 & 3 \\
\hline 8 & MS1IBA & IBA $1 \mathrm{mg} / \mathrm{L}$ & 3 & 2 & 2 & 2 & 14 & 14 & 10 & 9 & 1 & 1 & 1 & 0 \\
\hline 9 & MS2IBA & IBA $2 \mathrm{mg} / \mathrm{L}$ & 4 & 3 & 2 & 2 & 17 & 15 & 14 & 11 & 1 & 1 & 0 & 0 \\
\hline 10 & MS3IBA & IBA $3 \mathrm{mg} / \mathrm{L}$ & 5 & 4 & 3 & 3 & 19 & 17 & 16 & 14 & 1 & 1 & 0 & 0 \\
\hline
\end{tabular}

Note: ME-Mature Embryo, LB- Leaf Base

The organogenic callus formation from mature embryo cultures varied from $15 \%$ to5\% (Table 2). Maximum organogenic calli formation was observed from cv. JO-1 (20\%) and minimum by OS-6 (5\%). The performance of culture media MS3B.1N (20\%) and MS\$B.1N (20\%) were found to be high in terms of organogenic callus induction.

\section{Leaf base culture}

The mean callus induction frequencies from leaf base cultures varied from $85.0 \%$ to $5 \%$ (Table 2). Maximum callus induction was evident from JO-1 (85.0\%) and minimum by both JO-1 and OS-6 (5\%). Among different culture media, MS6D (85.0\%) and MS2D 
(70.0\%) were found the best. The minimum response was exposed by inoculation media MS0 (5\%).

The overall formation of embryogenic calli varied from $90 \%$ to $0 \%$ (Table 2). Most embryogenic callus was generated from JO-1 $(90.0 \%)$ and least by OS-6. No response on MS0. The performance of culture media MS2D (90.0\%), MS3IBA (85.0\%), MS2IBA (75.0\%) and MS2IBA (75.0\%) was found to be better.

The organogenic callus formation from leaf base cultures varied from $0 \%$ to $20 \%$ (Table 2). Higher organogenic calli formation was observed from JO-1 (20\%), JO-1and lower by OS-6 (0\%) and also JO-1 (0\%). Among culture media response to in vitro culture, the performance of culture media MS2B.1N $(20.0 \%)$ was found to be higher. The low response was exposed by inoculation media MS1IBA (0\%), MS2IBA (0\%) and MS3IBA $(0 \%)$.

Here attempt has been made to develop a simple procedure to regenerate popular oat cultivars JO- 1 and OS-6 with the use of BAP, NAA, IBA and 2,4-D. All these different growth regulators were used for the various stages of the regeneration. This study revealed that oat plants can be produced by using these growth regulators with its proper concentrations. These findings will helpful to perform the genetic transformation study in the Oat cultivars.

\section{References}

Choubey, R.N., Zadoo, S.N. and A.K. Roy 1996. Analysis of forage yield and related traits in back-cross derived progenies of interspecific matings (Avena sativa $\mathrm{x}$ A. sterilis) of oats. Crop Improv. 23 (1):155-157.

Gless, C., Lorz H. and A. Jahne-Gartner 1998. Establishment of a highly efficient regeneration system from leaf base segments of oat (Avena sativa L.). Plant Cell Rep., 17: 441-445.

Kim, K.H., Moon, J.H. and S.K. Lee 2004. Improvement of regeneration efficiency from mature embryo and leaf base segment in Korean oat Genotypes. Korean J. Crop Sci., 49: 349-353.

Murashige, T. and F. Skoog 1962. A revised medium for rapid growth and bioassays with tobacoo tissue cultures. $P l$. Physiol., 15: 473-497.

Pawlowski, W.P. and D.A. Somers 1998. Transgenic DNA integrated into the oat genome is frequently interspersed by host DNA. Proc Natl. Acad. Sci.USA, 95:12106-12110.

Somers, D.A., Rines, H.W., Gu, W. Kaeppler, H.F. and W.R. Bushnell 1992. Fertile transgenic oat plants. Biotechnol, 10: 1589-1594.

\section{How to cite this article:}

Salunke, M.D., B.U. Rathod and Dattagonde, N.R. 2017. In Vitro Regeneration of Oat (Avena sativa L.) Using Different Explants. Int.J.Curr.Microbiol.App.Sci. 6(12): 434-440.

doi: https://doi.org/10.20546/ijcmas.2017.612.053 